\title{
Sistema de interacción (low-tech) para pieza de arte Move-on
}

\section{Interaction system (low-tech) for art piece Move-on}

DOI: $10.46814 / 1 a j d v 4 n 1-018$

Recebimento dos originais: 03/01/2022

Aceitação para publicação: 15/02/2022

\section{Agustín Linares Pedrero}

Dept. de Bellas Artes, Facultad de Bellas Artes, Universidad de Málaga

29071 Campus El Ejido Málaga, España

E-mail: pedrero@uma.es

\section{RESUMEN}

Este artículo trata de exponer un sistema alternativo (y algo rudimenta-rio) para establecer una comunicación con el ordenador, en la que participan sen-sores muy simples, los cuales mandan una señal que es interpretada por el orde-nador (como pulsación de tecla) para activar un comportamiento multimedia. Con-templando la eficacia que requiere para su funcionamiento, a tal propósito se expone una instalación artística de carácter interactivo, Move-on, en cuyos procesos se necesita disparar el uso de animación fotográfica y el encendido de unos focos. La instalación establece una comunicación con el espectador a través del cuer-po, más concretamente, del movimiento de su propio cuerpo.

Palabras clave: interactividad, movimiento, arte, sensores.

\begin{abstract}
This article tries to expose an alternative (and somewhat rudimentary) system to establish a communication with the computer, which involves very simple signals, which send a signal that is interpreted by the computer (as a keystroke) to activate a multimedia behavior. In view of the efficiency required for its operation, an interactive artistic installation, Move-on, was created for this purpose, in whose processes it is necessary to trigger the use of photographic animation and the lighting of spotlights. The installation establishes a communication with the spectator through the body, more specifically, through the movement of his own body.
\end{abstract}

Keywords: interactivity, movement, art, sensors.

\section{INTRODUCCIÓN}

El arte asimila con rapidez todas las herramientas [1] y técnicas que van surgiendo a lolargo de la historia, desde la tecnología de la emulsión del óleo y el lienzo, que revolucionó la pintura haciendo que se pudiera pintar sobre tela enrollable y transportable, hasta la fotografía y el cine, que en un primer momento aparecen como un invento que procesa la imagen y más tarde, a fuerza de su uso y experimentación, encuentra su propio lenguaje y soporte expresivo, convirtiéndose en toda una nueva disciplina. Desde la irrupción del ordenador en el mundo del arte ya sehan generado estéticas 
propias como resultado de esta relación y se ha incorporado como una herramienta más en la producción artística por medio de la instalación, la cual utiliza para su desarrollo diferentes medios expresivos, y en este caso, los nuevos medios. [2]

Para establecer una comunicación entre persona y ordenador existen muchos interfaces en el mercado y muchos protocolos de programación. Uno de los que más está proliferando a la hora de desarrollar proyectos e instalaciones de arte es el uso de Arduino programado con Processing [3], pero, para el artista, a veces laprogramación es un tema muy árido y complejo, aún más si cabe, si la idea de la obrarequiere manejar varios videos y/o animaciones. Es por esto que se propone un sistema alternativo para la ejecución de dichos proyectos.

\section{DESCRIPCIÓN DE LA OBRA}

La idea a representar es que permanecer impasivos nos hace "envejecer conceptualmente" y el estar activos, en acción, nos hace mejorar nuestras capacidadescognitivas y físicas.

La instalación "Move-on" consiste en una proyección sobre una pared donde aparecen una sucesión rápida de fotografías de rostros de ambos sexos. Puede apreciarse que los rostros que aparecen pertenecen a personas muy ancianas. A la vez, a ambos lados y apoyados en el suelo, existen unos focos de luz roja que parpadean cada segundo.

Cuando un espectador se coloca delante de la proyección, si permanece inmóvil no sucede nada, continua lo antes descrito en un bucle; pero, cuando el espectador se desplaza lateralmente, intervienen los sensores haciendo que se apaguen los focos rojoslaterales. También los rostros de las personas van cambiando paulatinamente a personas de menor edad. Mediante acción y reacción, el espectador descubre que, si se mantiene en movimiento, las imágenes que se muestran van cada vez a más jovenhasta llegar a imágenes de bebés de menos de un año; en el momento que deja de desplazarse y moverse, los rostros se tornan en personas mayores de las que se están exhibiendo. Este proceso se da paulatinamente hasta llegar al bucle de las personas más ancianas, donde comienzan otra vez los focos a parpadear. 
Fig. 1. Esquema de representación de la instalación, compuesto por proyector, ordenador, circuito de teclado, 2 sensores conectados al teclado y 2 focos conectadosa un relé, conectado a su vez al teclado.

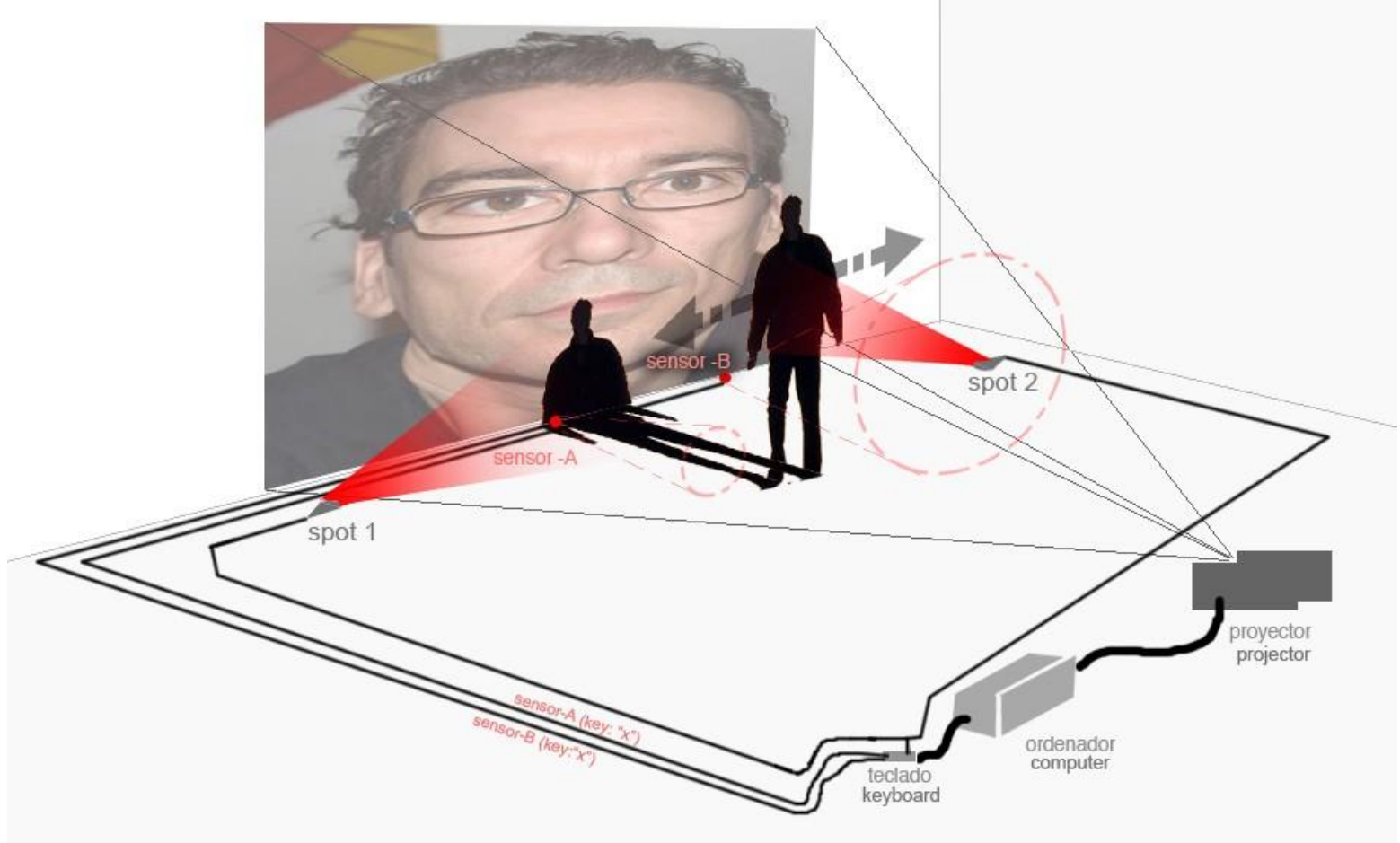

\section{DESCRIPCIÓN TÉCNICA}

Está pieza se aborda actuando sobre el hardware y sobre el software, los cuales pasamos a describir por separado.

\subsection{ACTUACIÓN SOBRE EL SOFTWARE}

El software principal que se utiliza es Flash (Adobe, anteriormente de Macromedia), mediante código ActionScript2 [4] y la configuración en capas. Sobre la línea de tiempo se distribuyen los diferentes elementos.

Esta película flash, en concreto, se reproduce a una tasa de 18 frames por segundo. La animación se realiza usando 13 grupos compuestos por 9 fotos cada uno, etiquetados de menor a mayor en edad a lo largo de la línea de tiempo. Cada grupo tiene mayor edad que el anterior y con ello se consigue que el video avance de forma natural hacia la ancianidad si no existe pulsación de tecla. Una vez la reproducción llega al grupo más anciano (etiquetado en el primer fotograma de su grupo como "80ytantos") el video reproduce solo este grupo en bucle (este es el modo reposo en ausencia de estímulos) y se consigue colocando la instrucción "AS2" en el último fotograma de dicho grupo. 
Cada grupo tiene en otra capa (pero coincidiendo en el tiempo) un botón con la siguiente programación para la pulsación de la tecla " $x$ ":

on (release, keypress " $x "$ ") \{gotoAndPlay ("el nombre dela etiqueta anterior") \}

De está forma (pulsando la misma tecla), según el grupo en el que se encuentre la reproducción, correrá hasta el grupo anterior, y si no hay pulsación, la reproducción continuará su marcha lógica hacia delante, hacia la ancianidad. Ejemplo: Si esta reproduciéndose el grupo etiquetado con "50ytantos", en caso de pulsar "x", la reproducción saltará hasta el grupo "40ytantos", y así sucesivamente. Si no hay pulsación de "50ytantos”, pasará al grupo "60ytantos”, y así sucesivamente.

Cada botón tiene su campo de acción limitado a solo dos fotogramas dentro de su grupo, de tal manera que el paso de un grupo a otro será gradual, pasando necesariamente sobre las 6 primeras fotos del bucle antes de poder cambiar a "anterior"o "siguiente". En resumen, el código será el siguiente:

Botón

Acciones para Botón:

on(release, keyPress "x") \{gotoAndPlay ("80ytantos") \}

Botón

Acciones para Botón:

on(release, keypress "x") \{gotoAndPlay ("70ytantos") \}

Botón

Acciones para Botón:

on(release, keypress "x") \{gotoAndPlay ("60ytantos") \}

Botón

Acciones para Botón:

on(release, keypress "x") \{gotoAndPlay ("50ytantos") \}

Botón

Acciones para Botón:

on(release, keypress "x") \{gotoAndPlay ("40ytantos") \}

Botón

Acciones para Botón: 
on(release, keypress "x") \{gotoAndPlay ("30ytantos") \}

Así sucesivamente. Según el número de grupos que tengamos, deberemos crear la misma cantidad de botones. A cada grupo de imágenes en bucle asignaremos un botón.

En el primer fotograma del último bucle introducimos una acción para frame 1 para que la pieza comience directamente en el estado de reposo. La línea de código sería:

$$
\text { gotoAndPlay ("80ytantos"); }
$$

Esta descripción hace que la animación a representar se comporte como necesitamosy como en un principio hemos descrito. Ahora bien, necesitamos algo más para poder conseguir una respuesta o actuación del ordenador, lo que hará que los focos se enciendan y apaguen en el estado de reposo de la obra.

Por un lado, debemos introducir en un nuevo código AS2, y por otro debemos crear unos controladores ejecutables que hagan encender y apagar el LED del teclado correspondiente, en este caso, a "numLock". Aprovechando esa carga eléctrica haremos activar un relé que haga disparar la luz de los focos si así lo deseamos.

\subsubsection{Actuación sobre numLock}

Este código programado en c++ simula la pulsación de las teclas "numLock" y "capsLock, mediante la que podemos encender y apagar el correspondiente LED del teclado. Se han creado dos ficheros ejecutables diferentes para cada tecla, uno para encender y otro para apagar el LED. Esto es necesario para poder ejecutar estas acciones desde código Flash. A continuación se muestra solo el código creado para encender y apagar el LED "numLock", ya que es prácticamente el mismo código usado para el LED "capsLock"; únicamente habría que sustituir la constante "VK_NUMLOCK" por la constante "VK_CAPITAL" en el caso de necesitar más tiposde actuadores:

\section{\#include <windows.h>\#include <WinAble.h>}

El siguiente código activará el led de "numLock" y por ende activará un relé al que está conectado poniendo en marcha los focos:

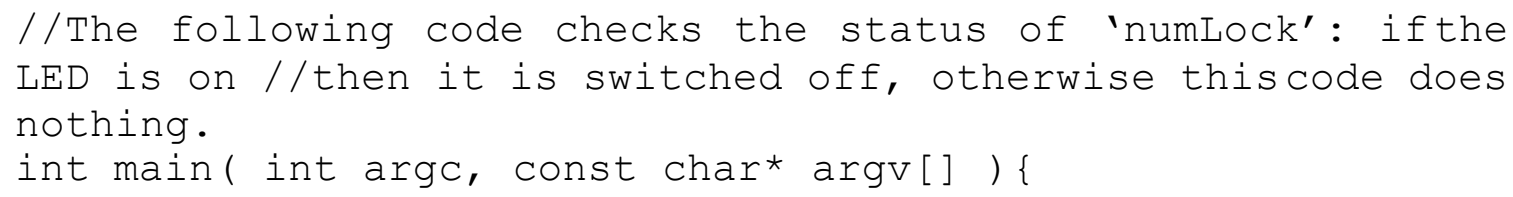




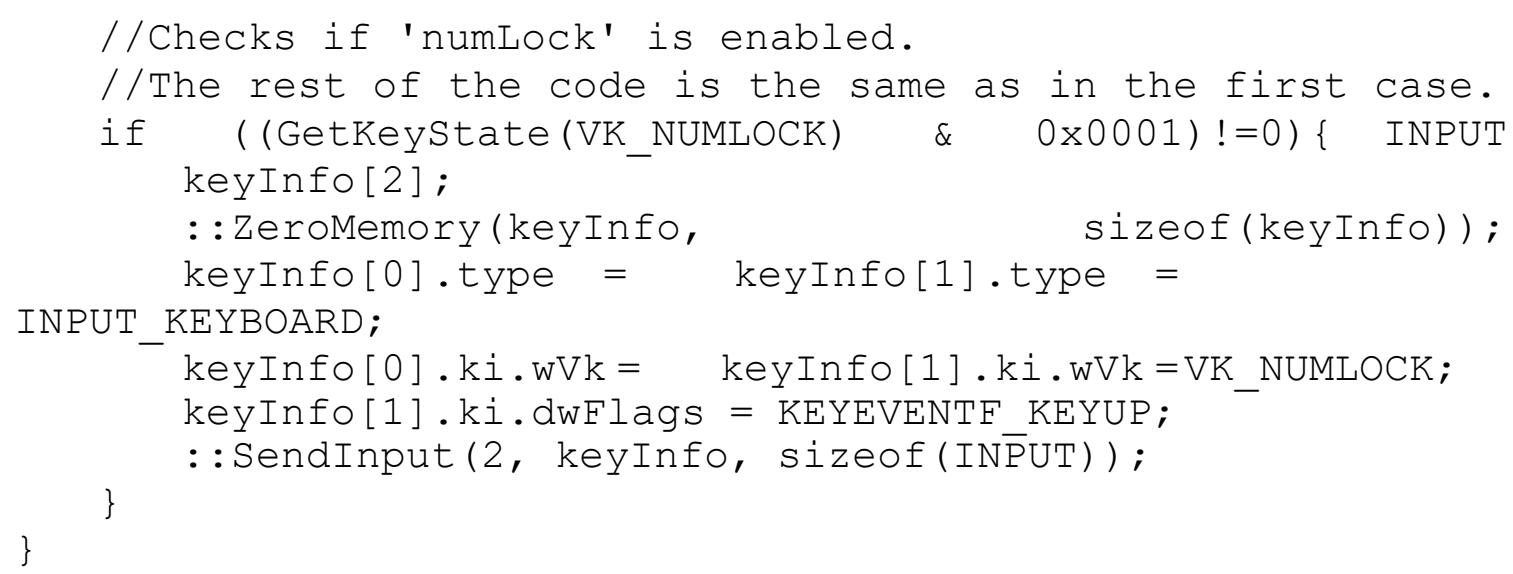

Este otro, en cambio, sirve para apagar el led de "numLock" y por ende desactivará el relé, apagando los focos:

//The following code checks the status of 'numLock: ifthe LED is off

//then it is switched on, otherwise this code does nothing .

int main( int argc, const char* argv[] ) \{

//Checks if 'numLock' is disabled.

if ( (GetKeystate (VK_NUMLOCK) \& 0x0001)==0) \{

key up

//We need two keyboard actions: key down and

input.

INPUT keyInfo[2];

//Fills the INPUT structure with zeros.

::ZeroMemory (keyInfo, sizeof(keyInfo));

//Specifies that we are sending a keyboard

keyInfo[0].type $=$ keyInfo[1].type $=$

INPUT_KEYBOARD;

//Specifies the key we want to activate. keyInfo[0].ki.wVk $=$ keyInfo[1].ki.wVk $=$ VK_NUMLOCK;

//This is the second action, key up. keyInfo[1].ki.dwFlags = KEYEVENTF_KEYUP;

//Finally the input is sent. :: SendInput(2, keyInfo, sizeof(INPUT)) ;

\}

Una vez que ya tenemos compilados cada uno de estos programas en un ejecutable

“.exe”, el paso siguiente consiste en ejecutar estos archivos desde el código "ActionScript2" mediante la siguiente sentencia: 


\section{fscommand("exec", "fileName.exe");}

Desde Flash, para que todo funcione, han de darse dos premisas: una que el proyecto Flash ha de exportarse como un ejecutable ".exe"; la otra es que los ficheros ".exe" creados de on-off han estar en una carpeta que debe llamarse "fscommand", y esta carpeta ha de situarse en el mismo directorio que el ejecutable flash.

\subsection{ACTUACIÓN SOBRE EL HARDWARE}

Una vez resuelta la parte de programación pasamos a describir como irá conectada la entrada y salida de señal por medio del circuito interno de un teclado.

Una vez hemos desmontado el teclado, en primer lugar, debemos averiguar qué dos conexiones activan la simulación de pulsación de la tecla " $\mathrm{X}$ ”. Las conexiones se pueden identificar por la línea de pins (vías por las que se conectan los vinilos de conexión) y consta de dos grupos, uno para cada filmina.

Fig. 2. Conexiones de una de los filminas o vinilos. Estas solo sirven para identificar los pins, no necesitamos conservarlas. $[5]$

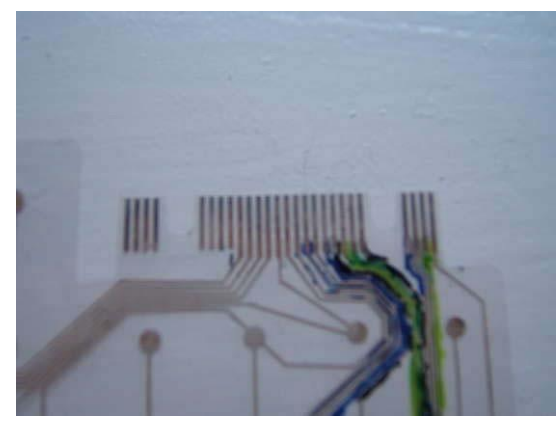

También mostramos la siguiente tabla que puede servir de guía.

Fig. 3. Tabla de conexiones del circuito del teclado (esta puede variar dependiendo del fabricante). Conviene hacer unas pruebas de tanteo y error para descubrir qué tecla es la que estamos activando. [6]

SIDE A

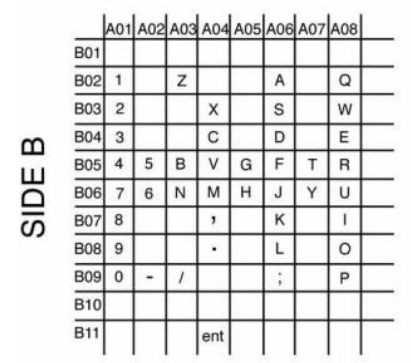


A nivel electrónico tenemos tres grupos bien diferenciados:

-Grupo A: Es el sensor, el cual introduce una señal on/off, ya sea por un sensor comercializado o por uno que desarrollemos (ver Fig.4.). En cualquiera de los casos puede llevar relé o puede llevar un transistor (suele ser del tipo 2N2222) para conducir la señal en caso de activación del mismo, ya que la carga requerida es debaja intensidad. En "Move-on" existen 2 sensores y van conectados a los pins conectores de la tecla.

-Grupo B: Es el actuador, la señal que hace encender el LED (en este caso el de "numLock") es aprovechada para activar la bobina de un relé, el cual hará de interruptor para encender los focos.

-Grupo C: Es el circuito del teclado, al que se conectan el grupo A y el grupo B según el siguiente esquema ilustrativo:

Fig. 4. Esquema de conexiones del circuito del teclado con los relés y sensores.

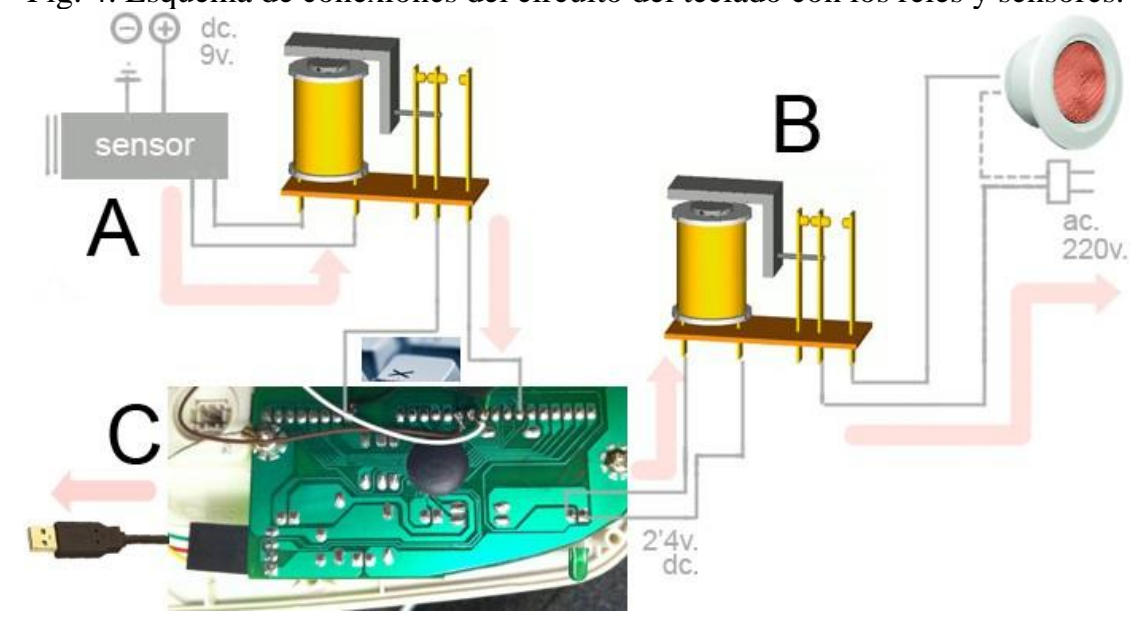

Fig. 5. Ejemplo del esquema de circuito para un sensor activado por la sombra, parael caso que nos ocupa. Según la cantidad de luz recibida sobre el componente (R1) (foto-resistencia) este hace activar/desactivar un relé. Puede calibrarse por medio del (R2) (potenciómetro de 50k). (Q1)=. 2N2222 y (D1)= 1N914. [7]

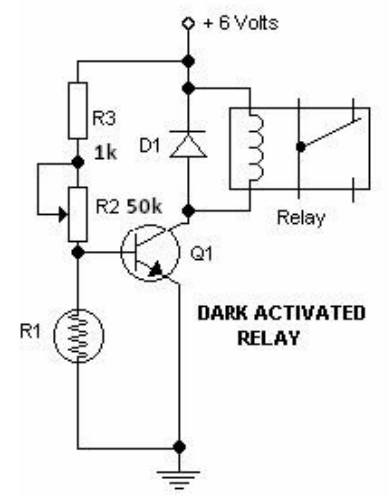

\section{CONCLUSIONES}

A nuestro parecer, se cumple la idea de representar los conceptos marcados por la interacción por medio de este método que, aunque rudimentario, resulta efectivo. 
Para la realización de esta instalación artística, según lo expuesto, tan solo se requieren conocimientos básicos en Flash (muchos artistas ya los tienen) y conocimientos básicos de electrónica (cómo funciona un relé), puesto que solo seusan los relés como conectores de entrada para las teclas y otros relés para la salida, conectados al led de "numLock".

La programación en c++ entraña unos conocimientos en programación algo más complejos, pero solo se usa en caso de necesitar actuadores (que el ordenador ordeneencender algún dispositivo, como un foco, por ejemplo), será entonces necesario utilizar los archivos en c++ "on/off” compilados en un ".exe”. Para ahorrarnos ese paso, los archivos podrán descargarse de Internet en la siguiente dirección: http://www.litiumlab.com/compilados/on-off.zip 


\section{REFERENCIAS}

Howard Rheingold, Tools for Thought: The History and Future of Mind-Expanding Technology (The MIT Press; 2 Rev Sub edition, 2000)

Bolter, J., \& Grusin, R. (1999). Remediation:Understanding New Media: Mit Pr.

Site official, http://processing.org

Site especializado en ActionScript, http://www.actionscript.org

Site de la revista digital Instructables, http://www.instructables.com/id/Hacking-a-USBKeyboard/step2/Trace-the-letters-back-to-the-pins/

Blog de "Collective Thinking”, http://thethoughttree.wordpress.com/2010/12/15/Site de electrónica, http://www.electroniq.net/other-projects/detectors/light-dark-switch-activated-relay-circuits.html 